Trans. xcvii. 249. Known quantities of the air to be tried, and of nitrous gas being mixed, were admitted.......into a graduated tube, which he [Priestley] denominated a eudiometer." This seems to point directly to Priestley as the author of the name as he certainly was the author of the process. (It may be mentioned in passing that, in this paper, Pepys describes the method of calibrating eudiometers, by pouring in equal quantities of mercury from a tube closed at one end and with the mouth ground flat, against which a piece of plate glass is pressed in order to obtain an exact measure of the mercury.)

With these directions I searched in the library of the Royal Society and found Magellan's book ; but he uses the name eudiometer as if it were well known. Mr. White, the librarian, very kindly interested himself in the matter and found in Priestley's book, "Observations on different kinds of Air," a statement that he had received from Landriani one of his eudiometers together with a description that he asks Priestley to print, but the latter excuses himself on the ground that it would not be convenient for him to publish the letter at that time. Mr. White found the title of a book by Marsilio Landriani, "Ricerche fisiche intorno alla salubrità dell" aria" (Milano, $\left.1775,8^{\circ}\right)$. It is not in the libraries of the Royal or of the Chemical Society, and the title does not appear in the catalogue of the library of the Royal Institution, but last week I found the book at the British Museum. On page viii. of the Intro duction there is a paragraph of which the following is a translation: "The account of the discovery of nitrous air and of some of its principal properties is briefly set forth, certain defects of Priestley's apparatus are removed, and there is added a detailed description of the Eudiometer, for that is the name which I give to my little instrument, from Eudios, a Greek word signifying goodness of the air (bontà dell' aria) accompanied by the more useful precautions for its construction." There are some plates at the end of the book containing drawings of the apparatus, and one of them is marked "Eudiometro I775." This seems to leave it without a doubt that it is to Landriani that we owe the word.

Next as to its exact meaning: by tradition we have been taught that the eudiometer is an apparatus for measuring the goodness of air, and this is obviously what was intended by Landriani, The New English Dictionary derives it from

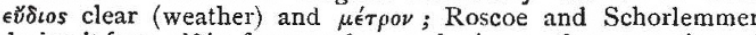
derive it from $\epsilon \dot{\nu} \delta i \alpha$, fine weather, and $\mu \epsilon ́ \tau \rho o \nu$; these meanings of the Greek words are no doubt correct, and the name would seem to be more applicable to some kind of weather glass, a signification which the above quotation shows could hardly have been in Landriani's mind.

Cooper's Hill, March 2 I.

\section{Blind Animals in Caves.}

Although in my previous letter I did not give evidence directly supporting the proposition that blind cave-animals are born or hatched with relatively well-developed eyes, that thesis is a good deal more than a mere supposition, as Prof. Lankester calls it. Nor did I, as Prof. Lankester asserts, proceed to state that no such fact is known or recorded. The condition of the eyes in the newly-born young of the viviparous Amblyopsis, or other cave-fishes, does not appear to have been investigated, although living young were born under observation as long ago as I 844 , and exhibited as spirit specimens to the Belfast Society of Natural History. Nor have the early stages of the European Proteus been obtained. But, on the other hand, with respect to cave crustacea, Tellkampf, the original describer of the blind Cambarus pellucious of the mammoth cave, stated that the eyes were larger in the young than in the adult (A. S. Packard, Amer. Nat. 1871), and Garman (Buli. Mus. Comp. Zool xvii. 1888-89) states that in very young specimens of $C$. setosus, the blind crayfish of the Missouri caves, "the eyes are more prominent, and appear to lack but the pigment." In another blind subterranean species, Troglocaris Schmidtii, occurring in Central Europe, Dr. Gustav Joseph found and demonstrated that the embryo in the egg was provided with eyes. (See Packard, "Cave Fauna of N. America," Nat. Acad. Sci. vol, iv. Mem. I.)

Thus, although it is obvious enough that further investigation of the development of cave-animals is required, it cannot be said that it is altogether a "hitherto unattempted embryological research." A discussion of this kind ought not, however, to be

NO. 1223 , VOL. 47 a mere logomachia. My purpose is to show that cave-animals afford a particular case of the general problem how to reconcile the law of recapitulation with the theory that adaptations or degenerations are explained by the selection of congenital variations. J. T. CUNNINGHam.

\section{The Value of the Mechanical Equivalent of Heat.}

IN NATURE for March 16 you published a summary of a communication which I had the honour to make to the Royal Society. My conclusion as to the value of the C.G.S. unit of heat was $4.1940 \times 10^{7}$ ergs (see NATURE, p. 478), and I added the following comment: "If we express Rowland's result in terms of our thermal unit we exceed his value by $\mathbf{I}$ part in 930 , and we exceed the mean value of Joule's (selected) determinations by one part in $350, \ldots .$. if we attach equal value to all the results published by Joule his value exceeds ours by I part in 4280 ."

I have received so many communications with regard to this last statement, that you will perhaps permit me to answer my correspondents through your columns.

I thought it unnecessary in a short summary to point out that the value (in gravitation and Fahrenheit units) result ing from Joule's own experiments is not the usually accepted 772.55 . To me it appears an extraordinary thing that 772 is to this day given in the text-books when, so far back as I880, Rowland conclusively proved that the results obtained from Joule's experiments give a higher value (see Proceedings, American Academy, March 1880).

In 1879 Rowland forwarded to Joule a thermometer by Baudin, which had been directly compared with Rowland's air thermometer. Joule himself then made a careful comparision of his therwometer with the Baudin one, and communicated the results to Rowland. The complete table is given on p. 39 of the paper already referred to. In addition to the correction thus show $\mathrm{n}$ to be necessary, further corrections for the capacity for heat of the calorimeter and contents were included, and as the results were published in Joule's lifetime, there can be little doubt but that these corrections received his approval.

I give an example (from p. 44) of Rowland's corrections :-

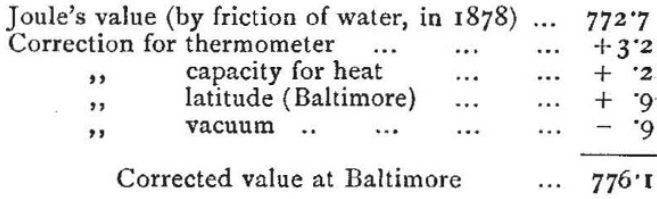

It is evident that Rowland did not claim for his air thermometry an order of accuracy greater than $\pm{ }^{\circ} \mathrm{O}^{\circ}$. In the appendix to his paper (p. 197) he remarks that if a certain improvement (not then adopted by him) was made, "it is probable that an accuracy of $0 I^{\circ} \mathrm{C}$. could be obtained from the mean of two or three observations. I believe that my own thermometers scarcely differ much more than that from the absolute scale at any point up to $40^{\circ} \mathrm{C}$."

A study of Rowland's methods, and of the tables given in his admirable paper, leads to the conclusion that it is possible that his thermometry is in error by $I$ in 1000 over the range $15^{\circ}$ to. $25^{\circ}$, and such an error would suffice to bring together the results (both in the value of $\mathrm{J}$ and in the temperature coefficient of the specific heat of water) obtained by Rowland and myself. The error would, however, but slightly affect the correction of Joule's results.

If we attach arbitrary values to Joule's later experiments, the mean of the corrected values (by Rowland's thermometer) is $776.75(g=32 \cdot 195)$; and the mean of all his determinations by various methods is $779^{\cdot 1} 7,^{1}$ and we may regard the above as within $I$ in 1000 of the value resulting from Joule's own work. on this subject.

I trust that in future our engineers and text-book writers will. (even if they ignore the work of later observers) do Joule the justice of discarding the traditional 772 , and adopt a value more in harmony with the investigations of that great experimentalist.

I2, Parkside, Cambridge.

E. H. GRIFFITHS

1 In terms of a thermal unit at $15^{\circ} \mathrm{C}$. 